\title{
LA INSTITUCIONALITZACIO DE LA SOCIOLOGIA A LA GRAN BRETANYA
}

\author{
Tom Bottomore \\ (University of Sussex)
}

La sociologia com a disciplina acadèmica no començà a arrelar-se a la Gran Bretanya fins després de la Segona Guerra Mundial. Durant els anys de guerra, l'àmbit de la sociologia es reduia a la LSE (London Scbool of Economics) i un sol catedràtic, a part de l'obra de Mannheim, que ja existia des del 1933. Però, per exemple, la seva obra Ideologia $i$ utopia va tenir una influència molt més gran ais Estats Units. En conjunt, la sociologia de la Gran Bretanya no tenia la importància cultural o científica que ja havia assolit a França, Alemanya o als Estats Units.

Les raons d'aquest retard són encara objecte de controvèrsies, però també d'estudis històrics més intensius, ja que la història de la sociologia en general cada vegada desperta més interès. Perry Anderson, en un assaig molt conegut en què compara la situació a la Gran Bretanya amb la de l'Europa Occidental, aftrma que l'absència de teptes als corrents de pensament que hi ha hagut des del marxisme com a teoria social general és l'explicació d'aquesta diferència. A la Gran Bretanya, suggeria, no hi havia cap necessitat d'una disciplina que pretenia descriute $i$ analitzar la societat d'una manera "objectiva» i de fet més conservadora en comparació a les idees més revolucionàries del maxxisme (cosa que sú hi havia, d'altra banda, a 1'Alemanya de Max Weber). La interpretació d'Anderson no se salva de les crítiques; aquest element no sembla haver estat gaire important si pensem en el sorgiment i creixement de la sociologia americana, que des del comen. çament ja va tenir el seu propi impuls radical o reformista; i aixó és aixî 
també en una part significativa de la sociologia eutopea, que sovint era més marxista o marxiana que no pas crítica del masxisme. Tanmateix, la telació amb el marxisme fou sens dubte un dels elements clau de la situació a la Gran Bretanya.

Un altre, evidentment, fou la posició fortament arrelada de la sociologia com a ciència social més important a les facultats d'Econòmiques; però això fa sorgir una quiestió interessant: per què alguns tipus d'idees, i sobretot les d'Aifred Marshall, que dutant un temps van dominar la disciplina econòmica, no van portar a una sociologia clarament articulada? Tal com el meu company Stefan Collini (que abans havia publicat un estudi sobre L. T. Hobhouse i els primers temps de la sociologia britànica) ha posat de manifest en un escrit recent, uns quants economistes de finals del segle XIX varen defensar la sociologia, però el punt de vista predominant sembla el que Alfred Marshall va resumir el 1885 en afirmat, tot referint-se a la idea de Comte sobre la ciència social unificada: «No hi ha dubte que si això existís, l'economia es posaria amb molt de gust sota la seva protecció. Però no existeix; no hi ha cap signe que indiqui que ha de començar a existir. No té cap sentit esperar inútilment; hem de fer el que puguem amb els nostres recursos actuals.»

Amb tota probabilitat, si llavors hi hagués hagut només una sola escola sota la influència moderada de les idees de Marx a la Gran Bretanya, l'economia acadèmica hauria estat objecte de crítiques més dures $\mathrm{i}$ la sociologia potser hauria esdevingut abans una disciplina universitària. En realitat, les dues fonts d'idees més importants en sociologia de la Gran Bretanya van romandre bastant allunyades de les universitats, i en general dels cercles intellectuals més prestigiosos (en contraposició a la manera ben diferent en què van ser rebudes les idees de Spencer als Estats Units $i$ al paper que van jugar allà en l'evolució de la sociologia).

A la fi, la sociologia no es va començar a establir, molt lentament i amb dificuitats, a les universitats fins aquest segle, $i$ els seus primers catedràtics procedien de filosofia (L. T. Hobhouse i Morris Ginsberg), d'història econòmica (T.H. Marshall) i de demografia (David Glass). D'altra banda, el que estava bastant arrelat a la Gran Bretanya des de la fi del segle $\mathrm{x}$ Ix eten els informes socials; des dels informes sobre les condicions de vida $i$ la pobresa realitzats per Booth $i$ Rowntree fins als estudis Mass Observation que varen iniciar a finals dels anys trenta Tom Harrison (antropòleg) i Charles Madge (poeta i sociòleg que va arribar a ser catedràtic de sociologia a la Universitat de Birmingham els cinquanta). Potser seria interessant de dir que l'arxiu de la Mass Observation és actualment a la Universitat de Sussex $i$ els historiadors socials l'utilitzen i l'inclouen en els seus estudis. La tradició dels informes socials és una de les influències que final- 
ment varen ajuctar a establir la sociologia a les universitats, encara que potser va ser més important a l'hora de crear els departaments d'administració social.

La institucionalització de la sociologia a la Gran Btetanya va començar en realitat, com ja he dit, després del 1945. T. H. Marshall, en la seva conferència inaugural com a catedràtic de sociologia a la LSE l'any 1946, es va referir a les onades d'estudiants que colpejaven les portes del departament de sociologia i va atribuir aquesta afluència al fet que aquelis que estaven investigant i tractant de resoldre els problemes de la societat de postguerra s'havien adonat que la sociologia no només era convenient, sinó fins i tot imprescindible per a la seva tasca. Raymond Aron, el 1953, en un apèndix del seu llibre sobre sociologia alemanya, escrivint en termes més dramàtics sobre el renaixement de la sociologia alemanya, deia que el llibre illusttava una vegada més «l'observació cruel i vulgar que les desgràcies històriques ajuden al desenvolupament de les ciències socials». Aquest comentari és vălid en molts paissos europeus després de la guerra.

Aquestes desgràcies varen encoratjar el desenvolupament de les ciències socials (i particularment de la sociologia), jo diria que tot dissolvent algunes de les rigideses de la societat d'abans de la guerra i difonent la idea d'una reconstrucció radical de la societat que eliminaria la misèria $i$ la injustícia de la dècada anterior. Alguns dels factors més influents a Gran Bretanya pel que $\mathrm{fa}$ al creixement de les ciències socials foren l'informe Beveridge del 1944, que dibuixava les línies generals del Welfare State, l'informe de l'any 1946 de la Comissió Clapham, que bavia estat establetta per tal d'estudiar la necessitat d'ampliar la investigació social i econòmica, i l'elecció el 1945 d'un govern laborista que es va veure obligat a dur a terme plans socials extensius per tal d'assolir la plena ocupació, ampliar l'assistència estatal (tot incloent un Servei Nacional de la Salut) i reformar el sistema educatiu.

Com a resultat d'aquests diversos factors (als quals hauríem d'afegir la influència de la sociologia americana i l'ajut a les investigacions sociològiques atorgat per les fundacions americanes durant els primers anys de desptés de la guerra), el nombre d'estudiants de sociologia, tant llicenciats com no liicenciats, va créixer considerablement durant els darrers anys quaranta i els primers cinquanta, sobretot al centre d'estudis sociològics més important d'aquell temps a la Gran Bretanya, la LSE. I d'aquest grup d'estudiants (un dels quals exa jo i Ralf Dahrendorf un altre) va sorgir durant la posterior expansió dels seixanta un percentatge considerable dels que actualment són catedràtics de sociologia. No obstant això, aquest grup no va constituir de cap manera una «escola» de sociologia (en el sentit en què es pot parlar d'una escola de Chicago, de Heildelberg, de Harvard o de Frankfurt). Aquí 
es barrejaven tipus molt diferents de sociologia: una continuació de les idees sociològiques de Hobhouse en el dibuix d'una teoria d'evolució social i "progtés»; un estudi històric i to teòtic comparat de les institucions socials a l'obra de T. H. Marshall; una prolongació de les investigacions demogràfiques dins l'estudi de la mobilitat social fet per David Glass (que durant anys va ser el punt de partida de la investigació empírica a la LSE); i finalment la infiltració dins un tot bastant tradicional i difús de les idees socials de la nova ( $i$ per a molts estudiants seductora o si més no provocadora) teoria de l'acció social de Talcott Parsons, que es va introduir directament a través de les ensenyances d'Edward Shils i va ser també una de les principals vies per on es va conèixer la sociologia marxista $i$ crítica durant un any que vaig estar a França, el 1951-1952.

Per tant, en els anys cinquanta, quan alguns estudiants de la LSE van arribar a donar classes als pocs departaments de sociologia en lenta expansió, no portaven amb ells un cos d'idees que representessin cap escola de pensament en concret, però tenien unes preocupacions distintives: la política social i el Welfare State i la mobilitat social especialment en telació al sistema educatiu. La primera conferència anual de la BSA (Britisb Sociological Association) el 1953 es va dedicat a tractar de «la política social i les ciències socials»; $i$ abans d'això, als darrers anys quaranta, com ja he dit, es va començar a realitzar un estudi a escala nacional sobre la mobilitat social sota la direcció de David Glass, el qual estudi va donar lloc posteriorment a una sèrie d'estudis comparats internacionals.

E1 més important és que aquests nous catedràtics tenien un clar ( $i$, en termes de cultura britànica, innovadot) compromís envers la sociologia com a disciplina acadèmica prioritària. De fet, va ser des d'aquesta època, eis primers anys cinquanta, que la sociologia va començar a estar fermament institucionalitzada a la Gran Bretanya. El 1950 es va fundar la BSA, que el 1955 ja tenia uns 450 membres, encara que una xifra important d'aquests també pertanyien a altres disciplines. El 1950 va aparèixer també el British Journal of Sociology, publicat per la LSE. Així va ser com, per primera vegada, la sociologia al Regne Unit va artibar a tenir la seva pròpia associació professional i erudita, així com la seva pròpia revista, mentre la seva importància dins les ciències socials en general exa cada cop més reconeguda.

Per tant, la infrastructura de la sociologia britànica es va establir durant els anys cinquanta, $i$ això va fer possible el ràpid progrés de la dècada següent. Durant els anys seixanta es van crear vint- - -vuit nous departaments de sociologia, alguns a universitats noves, i el grup de titulars de la LSE es va destacar molt en aquest sentit (eren unes quinze persones), malgrat que cap al final de la dècada també es va produir una contribució 
significativa d'altres centres d'estudis sociològics, sobretot de la Universitat de Leicester.

El creixement de la sociologia als anys seixantâ es reflecteix en l'increment del nombre de socis de la BSA i les seves activitats. Mentre jo vaig ser president de l'Associació (1969-1971), el nombre de socis va arribar a ser d'uns 1.200. Dos anys abans, el 1967, la BSA havia posat en maxxa la seva pròpia revista (Sociology), i durant el peŕode esmentat va començar a publicar una sèrie d'estudis curts («Studies in Sociology») i a crear grups especialitzats d'investigació entre els seus membres.

El fons destinat a la formació dels graduats $i$ a investigació va fer-se més abundant a mesura que augmentava el pressupost del SSRC (Social Science Research Council: Consell d'Investigació de la Ciència Social) i es va dedicar una quantitat més gran de pressupost a la sociologia (el 1971-1972 un $20 \%$ del pressupost del Consell es va dedicar a investigacions sociològiques i d'administració social; però per a anticipar-nos una mica direm que el 1979-1980 aquest tant per cent havia baixat al $7 \%$ d'un pressupost més reduit). Cap al final dels anys seixanta el nombre d'estudiants de sociologia (llicenciats i no licenciats) s'havia tornat a incrementar considerablement, tot formant part aquest increment d'un gran creixement de les ciències socials en general. Recordo que després del meu viatge al Canadà el 1968, quan vaig tomar a Sussex em vaig trobar cara a cata amb una concurrència de 25 estudiants diplomats; una xifra desorbitada en relació a les anteriors $i$ als nosttes recursos d'ensenyament.

Però la posició de la sociologia durant la dècada dels seixanta no va canviar només respecte a les xifres. Per primera vegada va quedar ben arrelada com una disciplina fonamental a les facultats de ciències socials de totes les universitats $i$ també a les politècniques $i$ les escoles, encata que aqui ho fes una mica més tard. On es reflecteix molt clarament aquesta evolució és a les noves universitats, totes les quals varen crear forts departaments de sociologia $i$ els atorgaven a vegades un lloc preeminent. Així, la Universitat d'Essex, per exemple, es va dedicar principalment a l'economia i la sociologia com dues bases de les ciències socials; a la Universitat de Sussex, la sociologia esdevingué una de les assignatures bàsiques (juntament amb l'economia i la història) de l'Escola de Ciències Socials. També va trobar el seu lloc en altres escoles (Euro, Afras, CCS). A Sussex hom pretenia promoure un creixement encara més fort de la sociologia dutant eis anys setanta, petò això es va frustrar a causa de la disminució financera que va començar el 1973.

Els temes tractats per la sociologia britànica varen començar a canviar profundament durant aquest període. Després del 1956, amb el triomf de la Nova Esquerra, es va renovar l'interès pel marxisme, i, més en general, 
per una teoria social «crítica» o «radical». Durant els anys seixanta, això va començar a produir una sociologia marxista més distintiva, o potser caldria dir que en va produir unes quantes versions. En tot cas, es va reconèixer a Marx el fet d'haver estat un dels «pares fundadors» de la disciplina, potser el més gran, i això va tenir dues conseqüències posteriors. La primera és que els altres pares fundadors (Durkheim i Weber) van començar a ser estudiats d'una manera més directa i crítica en relació a Marx; $i$, en el cas de Weber molt especialment, des d'una perspectiva diferent d'aquella interpretació que Talcott Parsons donava a entendre i gairebé establia com a norma ortodoxa. Evidentment, això no només va passar a la sociologia britànica; un fenomen semblant és àdhuc més acusat a la sociologia de la resta d'Europa i és obvi també a la sociologia americana dels anys seixanta. Particularment, recordo la reunió en el centenari de Weber de l'Associació Sociologica Alemanya l'any 1964. Es va caracteritzar per la confrontació entre Parsons i Marcuse i per l'èmfasi en el compromís de Weber en la política de força, que es va discutir en una altra sètie d'intervencions, com per exemple les de Raymond Aton i Wolfgang Mommsen. Al Regne Unit, l'obra que més bé expressava aquestes noves idees és probablement el llibre d'Anthony Giddens Capitalism and Modern Social Theory (1971), que situava històricament la sociologia en relació a l'evolució del capitalisme occidental, donava un paper molt important a la sociologia marxista $i$ analitzava, en el marc d'aquestes idees, les concepcions sociològiques de Weber i Durkheim. Això, crec, vâ representar l'absorciá per part de la sociologia britànica dels temes principals que el pensament sociològic clàssic tracta. va, temes que fins aleshores havien estat deixats de banda per una àmplia teoria social evolucionista bastant vaga i per la preocupació pels problemes de política social d'aquell moment o que havien estat vistos a través d'uns vidres massa parsonians.

Una segona conseqüència d'aquest impacte del pensament marxista (i, d'una manera més general, del seu renaixement) va ser el fet que es va relacionar la sociologia amb altres ciències socials, $i$, concretament, es va enfortir la unitat de les ciències socials (i també, no cal dir-ho, de la història social, dins la qual hi ha una llarga tradició de treballs marxistes a Gran Bretanya), $i$ es va veure que aquestes ciències subministraven un marc general per a tot tipus d'investigació $i$ anàlisi social.

Per a mi, el fet que durant aquesta època tesotgís notablement la polín tica econòmica marxista, després d'un període en què el marxisme havia estat deixat de banda gairebé del tot per part dels corrents dominants de l'economia acadèmica, és particularment important. Globalment, la influèrncia d'aquest fet es pot observar en el gir que es va fer cap a l'estudi dels problemes macroeconòmics, $i$ més concretament en les controvèrsies sobre 
el desenvolupament i el subdesenvolupament al Tercer Món. A la Gran Bretanya, com a tot arreu, Ia idea de «modernització» es veia desplaçada pels conceptes de creixement limitat i d'un sistema mundial amb societats "centrals» i «perifèriques»; $i$, en aquest canvi de conceptes, la teoria matxista (especialment la sociologia i la política econòmica) va jugat un paper molt important. Per exemple, a la universitat de Sussex, l'Institut d'Estudis sobre el Desenvolupament (Institute of Development Studies), que hom pot imaginat com un institut de ciències socials, s'ocupava especificament del Tercer Món, pels debats sobre idees del pensament marxista i també per la presència d'estudiants del Tercer Món, sobretot procedents de l'Amètica Llatina, Africa i Àsia.

Una altra àtea en què la sociologia marxista va comportar canvis de plantejament a la sociologia britànica fou l'estudi de la inadaptació i la mobilitat social. Jo he parlat abans de l'antic interès dels sociòlegs britànics per aquests temes, que s'evidenciava en l'estudi de la mobilitat social de finals dels quaranta, la monografia de T. $\mathrm{H}$. Marshall Ciutadania $i$ classe social $\mathrm{i}$ les investigacions sobre les desigualtats educatives i la pobresa (les segones han continuat fins avui especialment en els treballs de Peter Townshend). Però als estudis dels primers anys de després de la guerra es va posar èmfasi en la mobilitat social quant a la posició o status social i es va produir un relatiu abandó de les classes socials i l'estructura classista de la societat. Això també ha canviat ara i els sociòlegs han analitzat més completament i profunda l'estructura canviant de les classes socials en relació a l'economia i el sistema polític; això ha pottat un altre cop a una collaboració més estreta amb els economistes (en el caràcter concret del capital i la producció al Regne Unit) i amb els investigadors polítics (en el paper canviant de l'Estat a l'economia).

Per posar un tercer exemple del lloc que la sociologia ocupa dins les ciències socials, m'agradaria parlar de les discussions metodològiques de les dues datretes dècades. A la Gran Bretanya va ser sobretot a través de la sociologia (i de la seva ciència germana, l'antropologia), i en particular a través de la sociologia marxista (en l'obra d'Althusser i eIs seus seguidors), que l'«estructuralisme» es va introduir dins les ciències socials, on encara exerceix influència, malgrat que l'embat estructuralista ja hagi passat. No és sorprenent que l'estructuralisme hagi tingut aquesta influència, ja que la idea d' «estructura social» sempre ha ocupat un primer lloc dins la sociologia (i dins gran part de l'antropologia); però allò que va aportar l'estructuralisme modern va ser una idea més precisa i més ben formulada de l'estructura i l'anàlisi estructural, la qual cosa s'adiu particularment amb Ia noció marxista de «formacions socials» distintives històricament. Una altra vegada, voldria insistir en un aspecte particular d'aquesta situració: l'anàlisi 
estructuralista condueix la sociologia a una estreta relació amb l'economia (noves variants d'anàlisi macroeconòmica de l'economia) i amb les ciències polítiques (una anàisisi de l'estructura estatal i la seva relació amb la societat civil, o de la seva importància en els processos de formació de la societat en general).

Un altre important cortent de pensament metodològic, bastant oposat a l'estructuralisme $i$ inspirat en un ampli sentit per la fenomenologia, ha renovat la controvèrsia sobre un tema fonamentà a les ciencies socials en general i a la sociologia en particular. Es tracta de la relació entre les accions individuals i l'estructura social, entre la societat quant a realitat «subjectiva» o «construida» i la societat com a estructura «objectiva» donada. El debat ha estat molt ampli i ha portat a una reconsideració de les con. cepcions de Weber sobre l'«acció social» (i de l'elaboració que en va fer Schütz, més que la de Parsons), a la reformulació de la noció marxista de praxis i també a reconstruir la teotia marxista de Habermas a través del concepte de «comportament comunicatiu» i de la «sociologia de l'acció» proposada per Touraine. A la Gran Bretanya s'ha parlat molt d'aquests temes en els mateixos termes en què en parlen els escrits d'altres sociòlegs europeus, però, d'alguna manera, llurs idees han estat sintetitzades per Gid. dens, que durant els darrers anys ha elaborat les nocions d'《estructuración i «desestructuració» (construildes sobre l'ús que Gurvitch havia donat a aquests conceptes), que volen possibilitar una anàlisi sociològica que tingui en compte tant els elements estructurals com l'acció individual o de grup.

La meva intenció aquí no consisteix a analitzar en detall aquests debats teòrics i metodològics. El que jo vull destacar és que és degut en gran part al creixement de la sociologia i a la seva institucionalització com una de les principals assignatures a les facultats o escoles de ciències socials que aqquests debats sobre problemes bàsics dels mètodes $i$ teoria de les ciències socials s'han dut a terme d'una manera tan extensa i completa. I, en el seu decurs, s'ha tornat a posar de manifest una unitat subjacent de les ciències socials (si més no, com una aspitació necessària). El concepte d'«acción en sociologia té afinitats amb la idea d'uactor racional» en alguns tipus de teoria econòmica; està relacionat amb les controvèrsies entre historiadors sobre la història «narrativa» versus l'«estructural» i sobre la possibilitat d'una «història social científica», i fa revifar la qüestió de la relació que hi ha o hauria d'haver-hi entre una ciència social general i la psicologia individual o social.

El creixement de la sociologia a la Gran Bretanya ha estat acompanyat de dues característiques que m'agradaria esmentar breument, ja que també tenen una importància molt gran. Una, que és lògica en qualsevol ciència naixent, és el sorgiment d'àrees d'investigació més i més especialitzades. 
Això es fa evident en la gran varietat d'assignatures optatives (per exemple, la sociologia industrial, telacions racials, sociologia mèdica, etc.) que formen part del programa d'estudis de cada departament universitari de sociologia, la proliferació de grups d'investigació a la BSA i, és clar, a nivell internacional, en el gran creixement del nombre de Comitès d'Investigació de la ISA (International Sociological Association), des d'un o dos a principis dels anys cinquanta a uns 35 en aquest moment. Aquesta especialització, des del meu punt de vista, no perjudica el caràcter que la sociologia té de teoria social general, ja que les especialitzacions estan, en la seva majoria, clarament relacionades les unes amb les altres i fan servir gairebé exactament els mateixos conceptes $\mathrm{i}$ mètodes. Al mateix temps, són punts de contacte amb altres ciències socials i amb algunes disciplines a part de la ciència social.

La segona característica, a la qual ja he fet referència quan be parlat dels debats metodològics, és més pròpia de les ciències socials que de les traturals i destaca particularment en els moments actuals; em refereixo a la mateixa diversitat de punts de vista teòtics i metodològics. Una vegada hom va descriure la sociologia com una ciència que té «massa paradigmes». Això també vol dir molts plantejaments i criteris diferents sobre quins són els problemes centrals o més importants i pautes metodològiques distintes. I, avui, l'abundància de paradigmes sembla molt més gran que mai a molts. Al Regne Unit (però crec que la situació no és gaire diferent arreu) no hi ha evidentment un paradigma preeminent o dominant, però (i aquí potser s'estableix una diferència) tampoc no hi ha encara «escoles» de so. ciologia clarament constituildes, malgrat que existeixen, òbviament, alguns estils individuals diferents de treball.

Segons la meva opinió, aquesta situació no perjudica la importància de la sociologia o la seva influència. En primer lloc, és una situació que comparteix amb totes les altres ciències socials, malgrat que algunes, al Regne Unit si més no, n'hagin tingut menys consciència metodològicament. De tota manera, ara estan cada cop més compromeses en els debats (per exemple, l'economia i les ciències polítiques). En segon lloc, aquesta diversitat és una consequiència de la dificultat $i$ complexitat de la matèria en estudi que tothom reconeix (aquesta és Ia causa per la qual sempre hi ba hagut molts paradigmes, $i$ també discussions metodològiques a gran escala). També és una conseqǜència, en un context més ampli, de la confusíb i incertesa cultural generalitzades en un món en ràpida evolució, que potser són particularment intenses en aquest moment. Finalment, aquesta diversitat no anulla la coherència de la disciplina; hi ha per a tota aquesta varietat un nucil de conceptes teconeguts, que fan de la sociologia una ciència social i pesen en la seva presència substancial dins la universitat. 
El punt àlgid de l'expansió de la sociologia britànica es va produir cap al 1972-1973. Després d'això, primer es va produir un estancament i ales. hores, durant els darrers cinc anys, un descens gradual del nombre de pro. fessors i estudiants i del pressupost d'investigació. Però a la sociologia les coses no li han anat més malament que a altres ciències socials, of fins $i$ tot algunes branques de les ciències naturals (àdhuc les investigacions en medicina), les quals han vist reduir-se els seus recursos durant els últims anys. Entre les ciències socials s'ha produit una transferència dels fons de la sociologia a, per exemple, l'economia, i el SSRC ha canviat de nom i ara s'anomena ESRC, la qual cosa fa pensat un altre cop en un cert predomini de l'economia; però la disminució de la xifra de professors i estudiants de sociologia a les universitats ha estat més o menys proporcional a la dava. llada general. La sociologia continua estant fermament establerta com una ciència fonamental per a l'estudi global de la societat humana. La seva Associació és en molts aspectes més activa que mai, mentre que el nombre dels seus membres s'ha mantingut pràcticament constant, amb uns 1.000 socis de ple dret i de 300 a 400 estudiants i socis estrangers.

Des de la fi de la guerra, fa quaranta anys, la cultura britànica ha sofert canvis radicals, sobtetot durant la dècada dels seixanta. Un dels aspectes d'aquest procés de canvi $\mathrm{i}$ alhora també un dels seus motors és l'àmplia exparssió de les ciències socials, i entre ells la institució de la sociologia (pràcticament inexistent abans de la guerra) com una de les matèries centrals. Actualment, l'expansió s'ha aturat i àdhuc s'ha produït una davallada, però no crec que aquesta situació duri gaire. Hi ha dos factors que poden possibilitar un nou creixement de les ciències socials, segons la meva opinió. En primer lloc, totnant a la idea d'Aron segons la qual les desgràcies històriques estimulen el creixement de les ciències socials, crec que es pot affrmat que l'actual crisi social i econòmica, associada a canvis fonamentals en la tecnologia i l'organització del treball i la producció, portarà finalment a un nou creixement, especialment de la sociologia, en un esforç per tal de resoldre els nous problemes. En segon lloc, en la meva opinió existeix una tendència subterrània en les ciències socials (un altre cop, especialment en la sociologia) a ampliar-se dins les nostres societats cada vegada més «or* ganitzades»; no només organitzades en el sentit d'estar més regulades i planificades des de dalt, malgtat que aquest sigui un aspecte important, sinó en el sentit (gairebé oposat) d'estar compromeses en un procés d'«autoproducció» (tal com en parla Touraine) que tequereix, per part de tots els membres de la societat, eleccions conscients $i$ decisions basades en amplis coneixements socials.

Per tant, en conclusió, crec que la implantació de la sociologia al sistema educatiu de la Gran Bretanya després de la guerra i, d'una manera molt 
general, a la vida intellectual i cultural, ha estat una tesposta a les necessitats reals que experimenta la societat moderna. La sociologia ha esdevingut, encara que sigui tan inadequadament $i$ imperfecta com fins ara, la font principal de les idees $i$ concepcions mitjançant les quals tractem d'entendre i resoldre els grans problemes socials del nostre temps. Ara molta gent la mira sota aquesta Ilum i la seva influència dins les ciències socials ha crescut, jo diria que fins $i$ tot més que allò que les xifres demostren. L'antropologia i la sociologia estan més a prop que mai, una part considerable de les ciències polítiques s'ha transformat en sociologia política i dins l'economia hi ha àrees importants de treball que es podrien definit com a sociologia econòmica (o economia política). Però encara hauríem de treure una darrera conclusió d'aquests raonaments, que és que, tal com la meva experiència tant a la Gran Bretanya com al Canadà ha confirmat àmpliament, la mateixa sociologia creix més vigorosament i fructífera quan, dins un marc institucional adient, collabora estretament amb altres ciències socials $\dot{i}$, a part de contribuir-hi, també n'aprèn. 